\title{
Effectiveness of rotavirus vaccines against rotavirus infection and hospitalization in Latin America: systematic review and meta- analysis
}

Victor S. Santos ${ }^{1 *}$, Daniella P. Marques ${ }^{2}$, Paulo R. S. Martins-Filho ${ }^{1,3}$, Luis E. Cuevas ${ }^{4}$ and Ricardo Q. Gurgel ${ }^{1,2}$

\begin{abstract}
Background: Rotavirus was the leading cause of childhood diarrhoea-related hospitalisations and death before the introduction of rotavirus vaccines.

Methods: We describe the effectiveness of rotavirus vaccines to prevent rotavirus infections and hospitalizations and the main rotavirus strains circulating before and after vaccine introduction through a systematic review and meta-analysis of studies published between 1990 and 2014. 203 studies were included to estimate the proportion of infections due to rotavirus and 10 to assess the impact of the vaccines. 41 of 46 studies in the post-vaccination period were used for meta-analysis of genotypes, 20 to calculate VE against infection, eight for VE against hospitalisation and seven for VE against severe rotavirus-diarrhoea.

Results: $24.3 \%$ (95 \% Cl 22.1-26.5) and $16.1 \%$ (95 \% Cl 13.2-19.3) of cases of diarrhoea were due to rotavirus before and after vaccine introduction, respectively. The most prevalent $\mathrm{G}$ types after vaccine introduction were $\mathrm{G} 2$ (51.6\%, $95 \%$ Cl 38-65), G9 (14.5\%, $95 \%$ Cl 7-23) and G1 (14.2\%, $95 \%$ Cl 7-23); while the most prevalent P types were P[4] (54.1\%, $95 \% \mathrm{Cl} 41-67)$ and P[8] (33 \%, $95 \%$ Cl 22-46). G2P[4] was the most frequent genotype combination after vaccine introduction. Effectiveness was $53 \%$ (95 \% Cl 46-60) against infection, 73 \% (95 \% Cl, 66-78) against hospitalisation and $74 \%(95 \% \mathrm{Cl}$, 68.0-78.0) against severe diarrhoea. Reductions in hospitalisations and mortality due to diarrhoea were observed in countries that adopted universal rotavirus vaccination.
\end{abstract}

Conclusions: Rotavirus vaccines are effective in preventing rotavirus-diarrhoea in children in Latin America. The vaccines were associated with changes in genotype distribution.

Keywords: Rotavirus vaccines, Rotavirus vaccine effectiveness, Rotavirus genotype, Meta-analysis, Latin America

\section{Multilingual abstract}

Please see Additional file 1 for translation of the abstract into the five official working languages of the United Nations.

\section{Background}

Diarrhoea is the second most important cause of childhood death worldwide and rotavirus is the pathogen most frequently associated with severe diarrhoea [1].

\footnotetext{
*Correspondence: santosvictor19@gmail.com

'Postgraduate Program in Health Sciences, Federal University of Sergipe, Rua Cláudio Batista s/n, Aracaju, Sergipe Zip code: 49060-108, Brazil

Full list of author information is available at the end of the article
}

More than $90 \%$ of the deaths caused by rotavirus occur in low and middle income countries [2] and in Latin America (LA) alone, rotavirus diarrhoea caused $>70000$ annual hospitalisations and 15000 deaths between 1990 and 2009 [3].

In 2006, two live-attenuated rotavirus vaccines were licensed [4, 5], which was followed in 2009 by the World Health Organization (WHO) recommendation to include them in the national immunization programmes of all countries with high diarrhoea-related child mortality [6]. The vaccines licensed were the pentavalent (G1, G2, G3, G4, P[8]) human-bovine reassortant vaccine (RotaTeq ${ }^{\circ}$ (RV5); Merck, Whitehouse Station, NJ, USA) 
and the monovalent (G1P[8]) vaccine derived from an attenuated human strain (Rotarix ${ }^{\circ}$ (RV1); GlaxoSmithKline Biologicals, Rixensart, Belgium).

The LA region was among the early adopters of the vaccines with 16 countries and one territory introducing at least one of these vaccines in their national immunization programs. National programs have since reported significant reductions in severe rotavirus-diarrhoea episodes, allcause diarrhoea-related hospitalisations and ambulatory consultations [7-9].

Early reports also described that despite these reductions, a large proportion of rotavirus-diarrhoea episodes were associated with the heterotypic G2P[4] genotype $[10,11]$. This is often attributed to a temporal coincidence, as the genotype was circulating in countries with and without rotavirus vaccinations [3]; and to immunological pressure, as the vaccines could have facilitated the selection of genotypes for which they have lower efficacy [12]. Although similar changes have been reported from Belgium [13], Austria [14] and Australia [15]; a systematic review concluded that the genotype selection was unlikely to be due to a selective pressure and that further evidence is needed [16].

Rotavirus vaccines are being introduced in an increasing number of countries and the oldest cohorts of vaccinated children are approaching 10 years. This large scale regional experience has resulted in reports of vaccine effectiveness (VE) to prevent severe diarrhoea and hospitalisations. Recently, a systematic review of reports published between 2006 and 2013 estimated the VE against hospitalisation to range from 63.5 to $72.2 \%$ [17]. This review however did not measure the impact of the vaccines on the burden of rotavirus infection or changes in the frequency of rotavirus strains before and after vaccine introduction.

We conducted a systematic review and meta-analysis to describe the effectiveness of the vaccines to prevent rotavirus infection, hospitalisation and severe rotavirusdiarrhoea in LA and the frequency of rotavirus genotypes reported after vaccine introduction.

\section{Methods}

\section{Search strategy and selection criteria}

We conducted a systematic review using PubMed, the Latin American and Caribbean Health Sciences Literature (LILACS) and SCOPUS databases to identify studies published in Portuguese, Spanish and English between January 1990 and September 2014. Publications were identified using the search terms $\approx$ rotavirus", "rotavirus infection", "rotavirus vaccine" and related terms. The full search strategy is described in the Additional file 2. Two independent reviewers (VSS and DPM) screened the title and abstract for relevance. Articles considered to have original material were obtained and assessed in detail.
To assess the proportion of rotavirus in the pre- and post-vaccination periods, we included all observational studies (cohort, case-control, cross-sectional, case series and surveillance) that included children under 5 years of age with symptoms of acute gastroenteritis that had used Enzyme Immune-Assay (EIA) or Enzyme Linked ImmuneAssays (ELISA) for the identification of rotavirus. There were no clinical trials in the post-vaccination period. The pre-vaccination period was considered the time prior to the introduction of the vaccine in each country. For example, Brazil introduced the vaccine in March 2006, consequently all data reported from 1990 to before 2006 were considered pre-vaccination.

All studies in the post-vaccination period were included in the description of genotypes if they had used reverse-transcription polymerase chain reaction (RTPCR). For the description of strain distribution, we included studies reporting the number of samples tested and the $\mathrm{G}$ and $\mathrm{P}$ combinations.

To evaluate VE against rotavirus infection, we used all studies published in the post-vaccination period and to assess VE against rotavirus-related hospitalizations and severe diarrhoea, we included all case-control studies.

Studies reporting data before and after the introduction of the vaccine were used to assess the impact of the vaccine on the burden of rotavirus disease.

We excluded clinical trials conducted before vaccine licensure, articles without frequencies or percentages of rotavirus-positive children, studies including children with persistent diarrhoea ( $>2$ weeks' duration), those reporting nosocomial infections, rotavirus $\mathrm{B}$ and $\mathrm{C}$ infections or limited to outbreaks. There were no clinical trials conducted after the vaccines' introduction and therefore all studies included were observational.

\section{Data extraction}

Pre-defined tables for data extraction were developed and piloted with 10 papers. The information extracted included author, title, journal, publication year, country, start and end dates, study design, sample size, number of rotavirus-positive and negative samples (overall and by vaccination status), age range, study setting (hospital, hospital and community or community), vaccine type, rotavirus vaccine coverage, proportion of cases due to rotavirus, genotypes identified and frequency. Stool samples with rotavirus and co-infection with other pathogens were considered to be rotavirus-positive. Not all studies reported all variables and percentages were calculated using the number of studies reporting a given variable as the denominator. Countries were classified using the World Bank's classification for economic development [18] to describe the epidemiological context. To assess VE against rotavirus infection, we extracted the number of vaccinated and unvaccinated children 
who had rotavirus. To assess VE against rotavirusrelated hospitalisation and severe diarrhoea (defined as a Vesikari score $>11$ ), we extracted the odds ratio and its confidence interval from case-control studies. The studies' quality was assessed by two independent reviewers using the Newcastle-Ottawa Scale (NOS) [19].

\section{Statistical analyses}

Proportion of rotavirus diarrhoea and genotype distribution The overall incidence of laboratory-confirmed rotavirus diarrhoea and the proportion of P and G genotypes were calculated using the variance-stabilizing Freeman-Tukey double-arcsine transformation with an inverse-variance random-effects model [20, 21]. We used a Bayesian estimation for genotypes reported as $0 \%$. To make all proportions different to zero we added 0.5 isolates to the numerator and 1.0 isolates to the denominator. A Pareto chart was prepared to display the strains and cumulative genotype distribution.

The proportion of cases due to rotavirus diarrhoea by country was calculated using the arcsine transformation in a random-effects model. For countries with only one study, the prevalence and $95 \%$ confidence intervals (95\% CI) were calculated according to Newcombe's method [22]. Meta-analysis of single proportions was conducted in RStudio (version 0.98.1083).

\section{Vaccine effectiveness}

We expressed the protective effect of the vaccines as the relative odds reduction using the formula [100\% $\mathrm{x}(1-O R)]$. The odds ratio $(O R)$ was defined as the odds of laboratory-confirmed rotavirus infection in vaccinated patients divided by the odds of laboratory-confirmed rotavirus infection in unvaccinated controls.

The overall protective effect of rotavirus vaccination was estimated using the Mantel-Haenszel statistical model. In addition, to assess the VE in preventing hospitalisations due to infectious diarrhoea (any severity) and severe diarrhoea (Vesikari $>11$ ), the $O R$ and CIs were entered in the RevMan software (version 5.3; Cochrane Collaboration) under the generic inverse variance outcome. Forests plots were used to present the pooled $O R$ and $95 \% C I$. Two-sided $P$-values $<0.05$ were considered statistically significant.

Heterogeneity was investigated by the chi-squared test for heterogeneity and quantified using the $I^{2}$ index [100\% x (Q-df)/Q] [23]. The $I^{2}$ value ranged from 0 to $100 \%$, with 25, 50 and $75 \%$ expressing low, moderate and high heterogeneity, respectively. When $I^{2}>25 \%$, a random-effects model was applied to estimate the pooled results. Otherwise, the fixed-effects model was used.

Potential sources of heterogeneity were explored by comparing results grouped according to study-level characteristics and by using meta-regression to assess the significance of the differences. The characteristics explored were the vaccine type (RV1 vs. RV5), income (lower middle income vs. upper middle income countries), setting (hospital vs. hospital and community vs. community), latitude, and vaccination coverage. $\mathrm{R}^{2}$ index was used to quantify the proportion of variance explained by the covariates [23]. The assumptions of normality, independence, and homogeneity of residuals were verified using diagnostic plots.

Publication bias was assessed using funnel plots of the individual estimates in log units against the standard error and regression tests were performed to analyse the plot asymmetry.

\section{Results}

The search strategy identified 7151 records. After screening titles and abstracts, 392 full-text articles were assessed for eligibility and 215 were included. Of these, 203 were used to estimate the proportion of rotavirus, 157 in the pre-vaccine and 46 in the post-vaccine periods. Forty-one of the latter studies were used for genotype meta-analysis. VE was estimated based on 20 studies that reported the number of vaccinated and unvaccinated children. Of these, nine reported data on VE against hospitalisation and/or severe rotavirus-diarrhoea (Fig. 1).

One hundred and thirty-nine (64.6\%) of the 215 studies selected were cross-sectional, 29 (13.4 \%) cohorts, 21 (9.7\%) case-control, 14 (6.5\%) surveillance and nine (4.2\%) case series. Two hundred five (95.3\%) studies were hospital-based, eight (3.7\%) hospital and communitybased and 15 (6.9\%) community-based (Additional file 2).

\section{Proportion of rotavirus diarrhoea and genotype distribution}

Data extracted from 157 studies in the pre-vaccination period estimated that $24.3 \%$ (95 \% CI 22.1-26.5) were due to rotavirus. In the post-vaccination period, 46 studies provided data on the proportion of rotavirus cases (Additional file 2: Table S1). Overall, 9948 (16.1 \%, $95 \%$ CI 13.2-19.3) of 67,048 children tested for rotavirus infection were rotavirus-positive with the lowest and highest proportion of rotavirus-positive cases being reported from Nicaragua (10.5\%, $95 \%$ CI 6.3-15.6) and Mexico (26.7 \%, $95 \%$ CI 17.1-39.0), respectively. There was high-level heterogeneity across the studies $\left(I^{2}=99.1 \%, P<0.001\right)$. Table 1 describes the proportion of children with rotavirus-positive diarrhoea by country in the pre- and post-vaccination periods.

$\mathrm{G}$ and $\mathrm{P}$ type information was available for 5920 and 5845 isolates from 41 studies (Table 2). Most isolates were reported from Brazil, Nicaragua, and Colombia. G2 was the most prevalent $\mathrm{G}$ type (51.6 \%, $95 \%$ CI 37.8-65.3), followed by G9 $(14.5 \%, 95 \%$ CI 7.4-23.0) and G1 


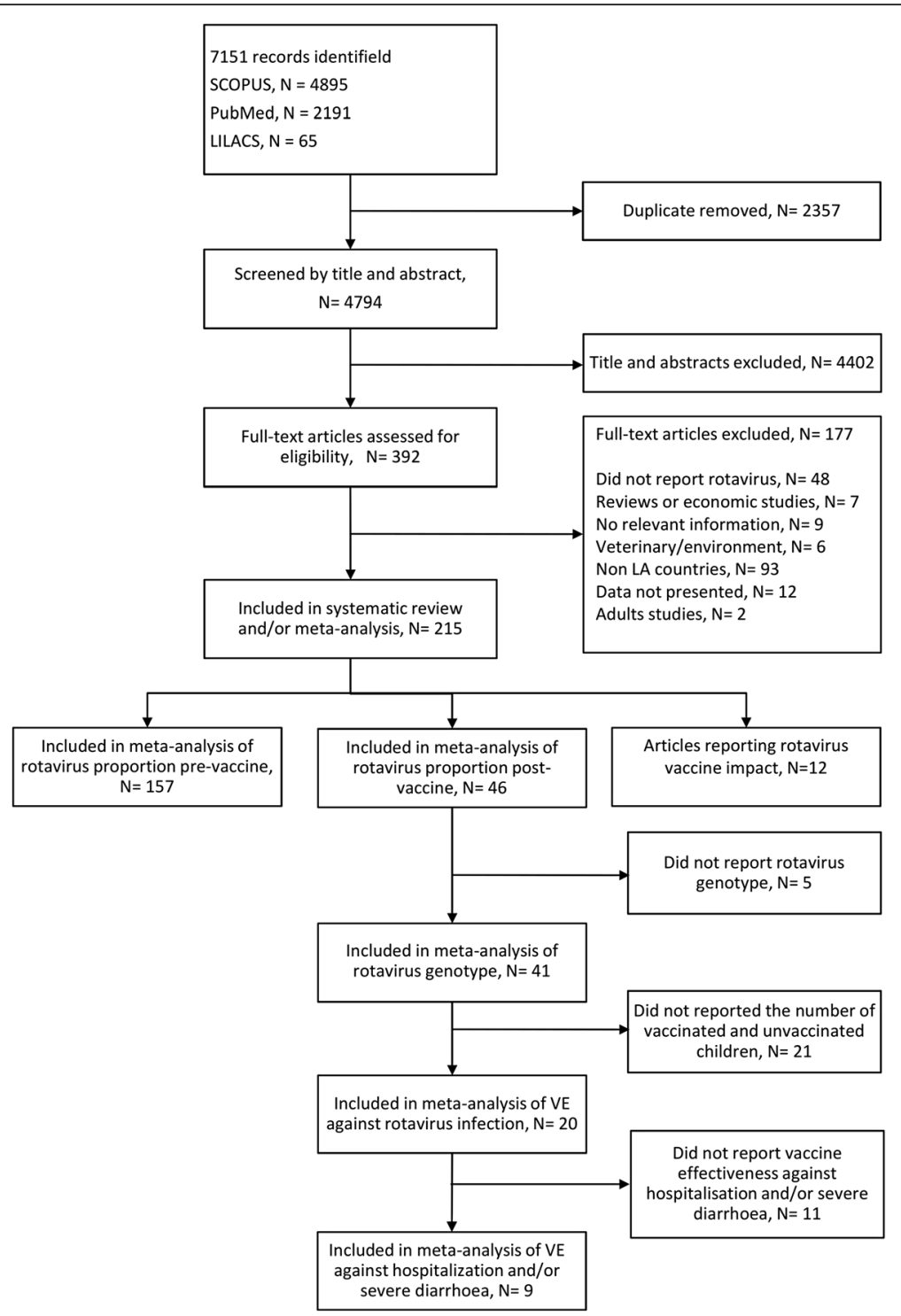

Fig. 1 Flow diagram of study selection

(14.2\%, $95 \%$ CI 6.9-23.3). The most common $\mathrm{P}$ types were $\mathrm{P}[4]$ (54.1 \%, $95 \%$ CI 41.3-66.5), $\mathrm{P}[8]$ (33.2\%, $95 \%$ CI 21.9-45.5), and P[6] (3.9 \%, $95 \% C I$ $1.7-6.7)$.

G2P [4] was the most prevalent G/P combination in Brazil (54.2 \%, 95 \% CI 32.8-74.9), Argentina (46.6\%, $95 \%$ CI 38.9-54.4), Ecuador (50.0 \%, 95 \% CI 33.6-66.4) and Colombia (57.3 \%, $95 \%$ CI 27.1-84.8) and the second most common combination in Nicaragua (20.3\%, $95 \%$ CI 0.2-54.6), Chile (6.8 \%, $95 \%$ CI 4.0-11.3) and Bolivia (28.9\%, $95 \%$ CI 23.7-34.7). The G9P [8] combination was most frequent in Chile $(81.7 \%, 95 \%$ CI 75.6-86.5) and Bolivia (41.8\%, $95 \%$ CI 35.9-47.9); and the second most frequent in Argentina (16.4 \%, 95 \% CI 1.3-41.8 \%), Ecuador (37.5 \%, $95 \%$ CI 22.9-54.8), and Colombia
(7.8 \%, $95 \%$ CI 3.0-14.4). G1P[8] (32.9\%, $95 \%$ CI 6.2-66.7), G9P[4] (100\%, $95 \%$ CI 80.6-100), and G12P[6] (33.3 \%, $95 \%$ CI 19.2-51.2) combinations were the main genotypes in Nicaragua, Mexico and Peru, respectively (Fig. 2).

\section{Vaccine effectiveness}

Twelve studies from upper-middle income countries (Argentina [24], Brazil [8, 10, 25-31], Mexico [32], and Venezuela [33]) and lower-middle income countries (Bolivia [34], El Salvador [35], and Nicaragua [36-41]), involving 15750 children were included for the overall analysis of VE. These included $2102(17.4 \%)$ rotaviruspositive cases among 12079 vaccinated and 996 (27.1\%) rotavirus-positive cases among 3671 unvaccinated 
Table 1 Proportion of children with rotavirus diarrhoea pre- and post-vaccination in Latin America

\begin{tabular}{|c|c|c|c|c|c|c|c|}
\hline \multirow[t]{2}{*}{ Country } & \multirow{2}{*}{$\begin{array}{l}\text { Year of introduction } \\
\text { rotavirus vaccine }\end{array}$} & \multirow[t]{2}{*}{ Vaccine } & \multicolumn{2}{|l|}{ Pre vaccine } & \multicolumn{2}{|c|}{ Post vaccine } & \multirow[t]{2}{*}{ Difference (\% } \\
\hline & & & Proportion & Cl $95 \%$ & Proportion & Cl $95 \%$ & \\
\hline Brazil & 2006 & RV1 & 21.1 & $17.7-24.7$ & 15.8 & $11.4-20.8$ & -25.1 \\
\hline El Salvador & 2006 & RV1 & 32.9 & $25.7-40.7$ & 19.7 & 18.9-20.6 & -40.1 \\
\hline Panama & 2006 & RV1 & 24.8 & $3.8-56.4$ & - & - & - \\
\hline Venezuela & 2006 & RV1 & 21.7 & $16.9-26.9$ & - & - & - \\
\hline Nicaragua & 2007 & RV5 & 18.9 & $14.8-23.6$ & 10.5 & $6.3-15.6$ & -44.4 \\
\hline Bolivia & 2008 & RV1 & 28.9 & $16.4-43.3$ & 17.3 & 15.8-18.9 & -40.1 \\
\hline Ecuador & 2008 & RV1 & 30.0 & $20.8-40.1$ & 18.8 & $15.3-22.9$ & -37.3 \\
\hline Peru & 2008 & RV1 & 24.9 & $16.7-34.1$ & - & - & - \\
\hline Colombia & 2009 & RV1 & 29.8 & $19.1-41.8$ & 18.4 & $16.1-20.8$ & -38.3 \\
\hline Honduras & 2009 & RV1 & 27.5 & $14.9-42.3$ & - & - & - \\
\hline Mexico & 2009 & RV1 & 19.8 & $12.3-28.5$ & $26.7^{\mathrm{a}}$ & $17.1-39.0$ & +34.8 \\
\hline Guatemala & 2010 & RV1 & 30.4 & $13.2-50.9$ & - & - & - \\
\hline Guyana & 2010 & RV1 & 8.1 & $5.5-10.1$ & - & - & - \\
\hline Paraguay & 2010 & RV1 & 25.3 & $19.4-31.7$ & - & - & - \\
\hline Dominican Republic & 2012 & RV1 & 61.9 & $57.1-66.6$ & - & - & - \\
\hline Argentina & - & - & 26.4 & $19.9-34.2$ & - & - & - \\
\hline Chile & - & - & 26.4 & $19.5-33.9$ & - & - & - \\
\hline Costa Rica & - & - & 44.7 & $32.6-57.1$ & - & - & - \\
\hline Cuba & - & - & 16.6 & $5.2-32.7$ & - & - & - \\
\hline Puerto Rico & - & - & 15.6 & $14.8-16.4$ & - & - & - \\
\hline St. Vincent & - & - & 25.2 & $18.1-33.0$ & - & - & - \\
\hline Surinam & - & - & 33.9 & $28.3-39.9$ & - & - & - \\
\hline Uruguay & - & - & 37.2 & $26.5-48.4$ & - & - & - \\
\hline
\end{tabular}

aased on only one study

children. The overall OR was 0.47 (95\% CI 0.40-0.54), resulting in an overall VE against diarrhoea infection of $53 \%$ (95 \% CI 46.0-60.0). VE was similar for RV1 (54\%, $95 \%$ CI 45.0-62.0) and RV5 (52 \%, $95 \%$ CI 36.0-64.0) $(P=0.79)$ (Fig. 3). There was moderate between-study heterogeneity $\left(P=0.08 ; I^{2}=33 \%\right)$.

$\mathrm{VE}$ to prevent diarrhoea-related hospitalisations (of any severity) and severe rotavirus-diarrhoea was based on eight $[26,34,35,40-44]$ and seven $[26,29,33,34$, $37,39,44]$ case-control studies, respectively. VE against rotavirus-related hospitalisations was $73 \%(95 \% C I$, 66.0-78.0), with moderate heterogeneity among studies $\left(I^{2}=29 \%, P=0.20\right)$. VE against severe rotavirus diarrhoea was $74 \%$ (95\% CI, 69.0-78.0) with no evidence of heterogeneity $\left(I^{2}=0 \%, P=0.55\right)$. The level of protection was similar for the two vaccines, as shown in Fig. 4.

To investigate the potential sources of heterogeneity among studies, a meta-regression analysis was performed by using variables as type of vaccine, setting, country income, latitude, and vaccination coverage.
Although the difference in protection by latitude was not significant in meta-regression $(P=0.258)$, it was the only factor that partly explained the heterogeneity (adjusted $R^{2}=22.3 \%$ ) (Additional file 2: Table S2).

The omission of any of the studies did not modify vaccine effectiveness, suggesting a high stability of the meta-analysis. There was no evidence of publication bias (Additional file 2: Figure S1).

Twelve studies assessed the impact of rotavirus vaccination in countries adopting universal rotavirus vaccination. Of these, five were conducted in Brazil [7, 44-48], four in Mexico [49-52], two in Panama [53, 54] and one in El Salvador [55]. In Brazil, vaccine coverage ranged from $80 \%$ in 2007 to $86 \%$ in 2009 . A substantial reduction in deaths (22.0\% to $54.5 \%$ reduction) and hospitalizations $(25.0 \%$ to $50.0 \%$ reduction) in children $<1$ year old was observed, compared to the pre-vaccination period. In Mexico, vaccination coverage remained above $90 \%$ from 2006 to 2011 with significant reductions in deaths and hospitalisations due to gastroenteritis. In Panama, national hospital database studies comparing 
Table 2 Rotavirus $G$ and $P$ genotype distribution in Latin America, 2006-2014

\begin{tabular}{llcl}
\hline Genotype & Isolates $(n)$ & Proportion (\%) & $95 \% \mathrm{Cl}$ \\
\hline G1 & 1501 & 14.2 & $6.9-23.3$ \\
G2 & 3170 & 51.6 & $37.8-65.3$ \\
G3 & 335 & 3.6 & $1.7-6.0$ \\
G4 & 97 & 0.3 & $0.0-0.8$ \\
G5 & 33 & 0.0 & $0.0-0.2$ \\
G8 & 29 & 0.0 & $0.0-0.04$ \\
G9 & 703 & 14.5 & $7.4-23.0$ \\
G10 & 1 & 0.0 & $0.0-0.2$ \\
G12 & 50 & 0.8 & $0.1-1.9$ \\
G un-typeable & 90 & 1.2 & $0.2-2.6$ \\
P[4] & 3208 & 54.1 & $41.3-66.5$ \\
P[6] & 327 & 3.9 & $1.7-6.7$ \\
P[8] & 2265 & 33.2 & $21.9-45.5$ \\
P[9] & 1 & 0.0 & $0.0-0.1$ \\
P[10] & 5 & 0.0 & $0.0-0.2$ \\
P un-typeable & 111 & 2.2 & $0.8-4.2$ \\
\hline
\end{tabular}

The proportions of genotypes were calculated by using random-effects model

diarrhoea-related hospitalisations and deaths prior (2000-2005) and after (2008) vaccination reported a $45 \%$ reduction in hospitalisations and $50 \%$ of deaths among infants aged $<1$ year old. Rotavirus vaccine coverage at that time was above $80 \%$. El Salvador reported a reduction in hospitalisation rates. Rotavirus vaccine coverage in 2008 and 2009 was 74 and $89 \%$, respectively (Table 3).

\section{Discussion}

Rotavirus-related diarrhoea is still an important public health problem in low- and middle-income countries and the early and widespread use of the vaccines in LA has resulted in a large number of studies and samples analysed, providing an excellent opportunity for their post-licensure evaluation. This meta-analysis estimated that rotavirus VE was $53 \%$ against rotavirus infections, $73 \%$ against rotavirus-related hospitalisations and $74 \%$ against severe diarrhoea episodes. The vaccines (RV1 and RV5) had similar effectiveness. These findings highlight the occurrence of significant reductions of hospitalisations and deaths, as well as decreases in the proportion of diarrhoea episodes due to rotavirus among the countries that adopted universal rotavirus vaccination.

The trials conducted for the registration of the vaccines included a large number of children from middleand high-income countries from Europe, North America and LA and their main end-points focused on severe diarrhoea episodes and hospitalisation. Their efficacy against severe rotavirus-diarrhoea ranged from 85 to $98 \%$ and rotavirus-associated hospitalisation ranged from 85 to $94 \%[4,5]$. In these trials however, vaccine efficacy for all-cause diarrhoea hospitalisation was only $39 \%$ and data on the efficacy of the vaccines to reduce infections was not reported [56]. Our findings reflect real-world outcomes, that are different from those reported under clinical trial conditions and seem to be lower than in Europe, where VE against hospitalisations ranges from 80 to $98 \%$ [57]. There seems to be a variation of the protective effect of the vaccine according to the setting, and trials in low/middle-income African

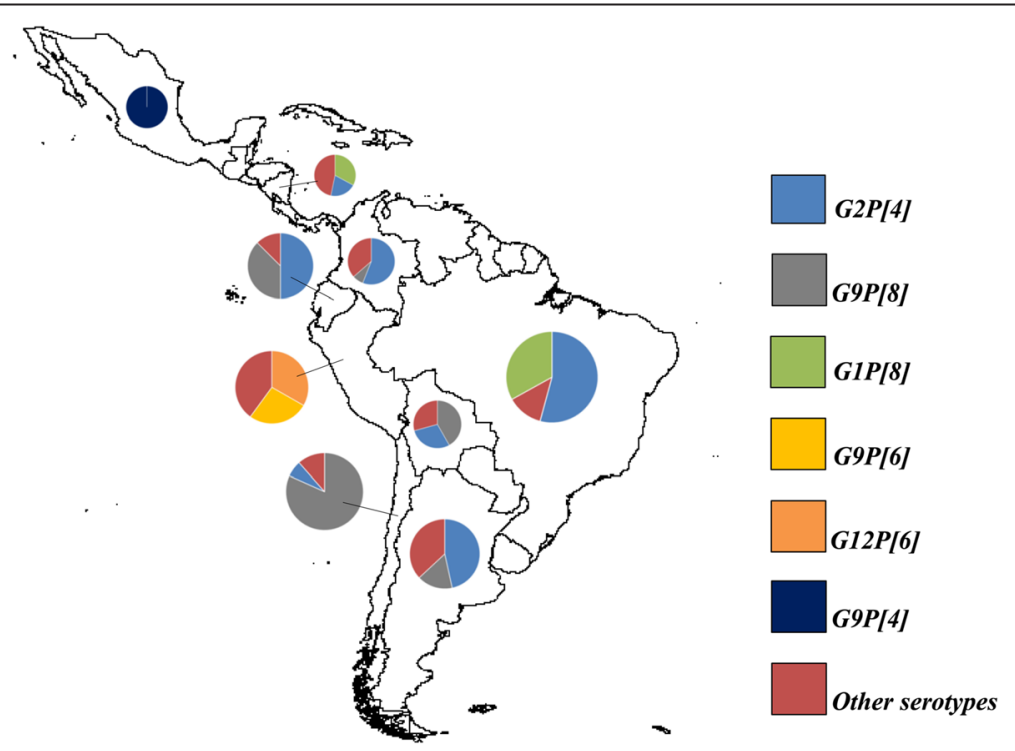

Fig. 2 Geographical areas in which rotavirus genotypes are prevalent 


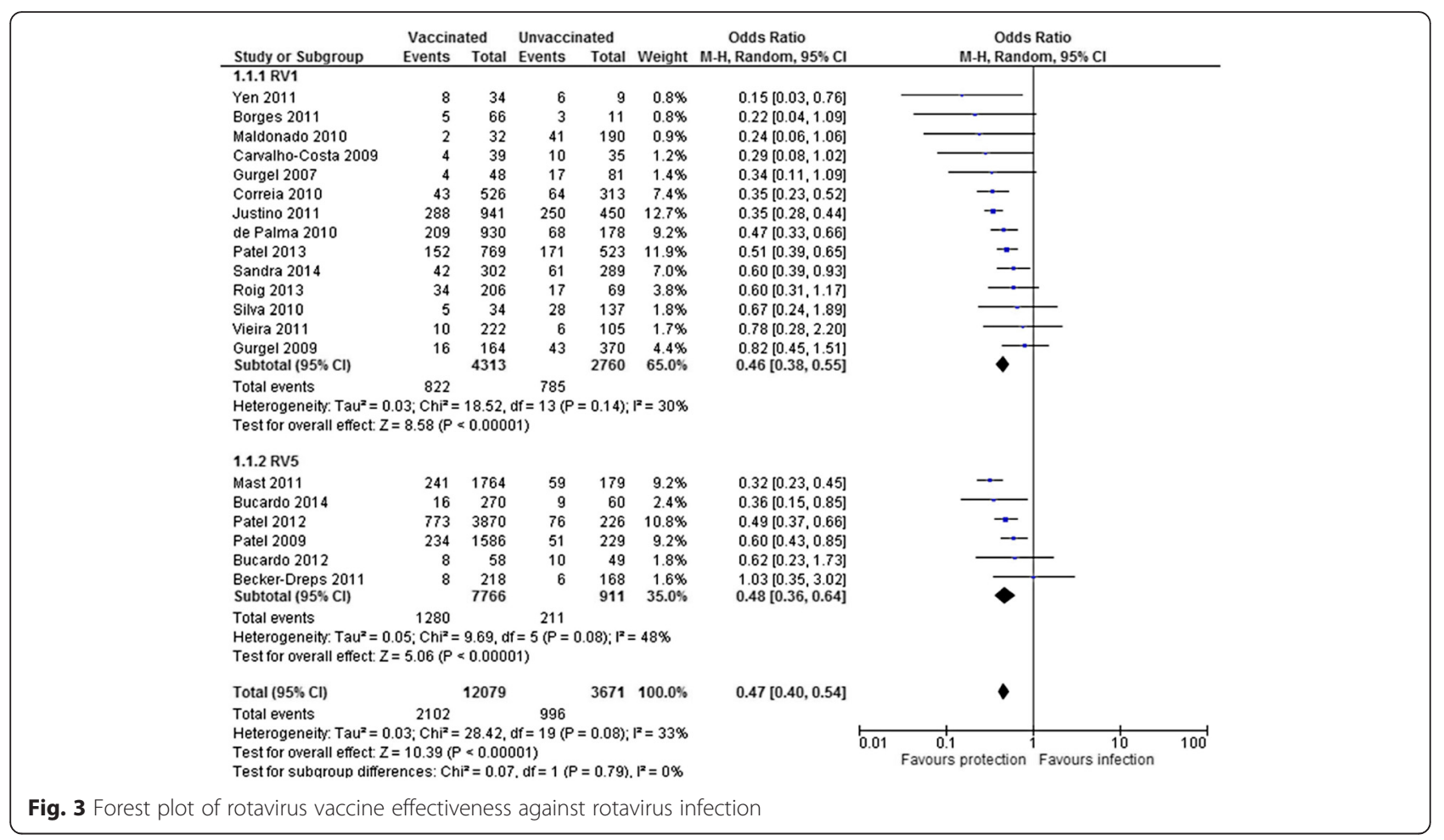

countries have reported a lower efficacy of the RV1 vaccine $[58,59]$, which could be due to the higher burden of disease in these settings.

This meta-analysis reinforces that the introduction of the vaccines reduces hospitalisations, and reduces the frequency of severe rotavirus episodes and deaths in children $<5$ years old. The studies summarised provide significant evidence of reductions in hospitalisations and deaths not only in children that received the vaccines, but also in older children. Similar data have been reported from Europe [57] and the United States [9], which may be due to a herd effect of the vaccine enhancing its impact when implemented at large scale under routine conditions. The reduction in hospitalisations and deaths would result in large cost savings [60]. It is estimated that from 2007 to 2025, universal vaccination could avert 141 medical visits for every 1000 children vaccinated in Latin America and save $>16000$ lives [61].

Overall, our findings show a decrease in the proportion of diarrhoea infections by rotavirus in the postvaccine era and provide further evidence that rotavirus vaccinations are associated with a reduction in rotavirus-diarrhoea morbidity. The $16 \%$ proportion of children with rotavirus infection is much lower than the proportion reported before vaccination introduction (range 24-47 \%) [3, 62, 63], but varied considerably among countries. This variability may be explained by differences in the burden of disease across study settings, the case definitions used; that some countries were represented by only one study and that some studies were conducted soon after vaccine introduction, which complicates the interpretation of data.

Historically, rotavirus genotypes before vaccines introduction varied over time and the peak frequency of one strain was often followed by a trough and replacement by a different genotype [64]. The strains found most commonly in LA before vaccines introduction were G1P[8], G9P [8] and in a lower proportion G2P[4] and these strains were similar to the most frequent genotypes reported worldwide [3, 64, 65]. After the introduction of the vaccines, a high proportion of studies reported that the highest number of cases were due to the G2P[4], especially in countries that adopted the RV1 vaccine. Similar changes were observed in Oceania [15] and Europe [13, 14, 66]. Latin American countries that did not adopt the vaccines up to 2012 (e.g. Cuba, Costa Rica and Dominican Republic) reported that a different strain (G9P[8]) was the most frequent circulating genotype (>75 \%) among their children with diarrhoea $[67,68]$.

A recent meta-analysis reported that vaccine protection against the G2P[4] strain is lower (39\% in Latin America and $58 \%$ in Europe) than for homotypic and partly-heterotypic strains ( $>80 \%$ protection) [16], suggesting that the RV1 vaccine may have favoured the selection of this strain in a highly vaccinated population [69]. However, a recent study in Brazil also reported a decrease of G2P[4] incidence from 2011 


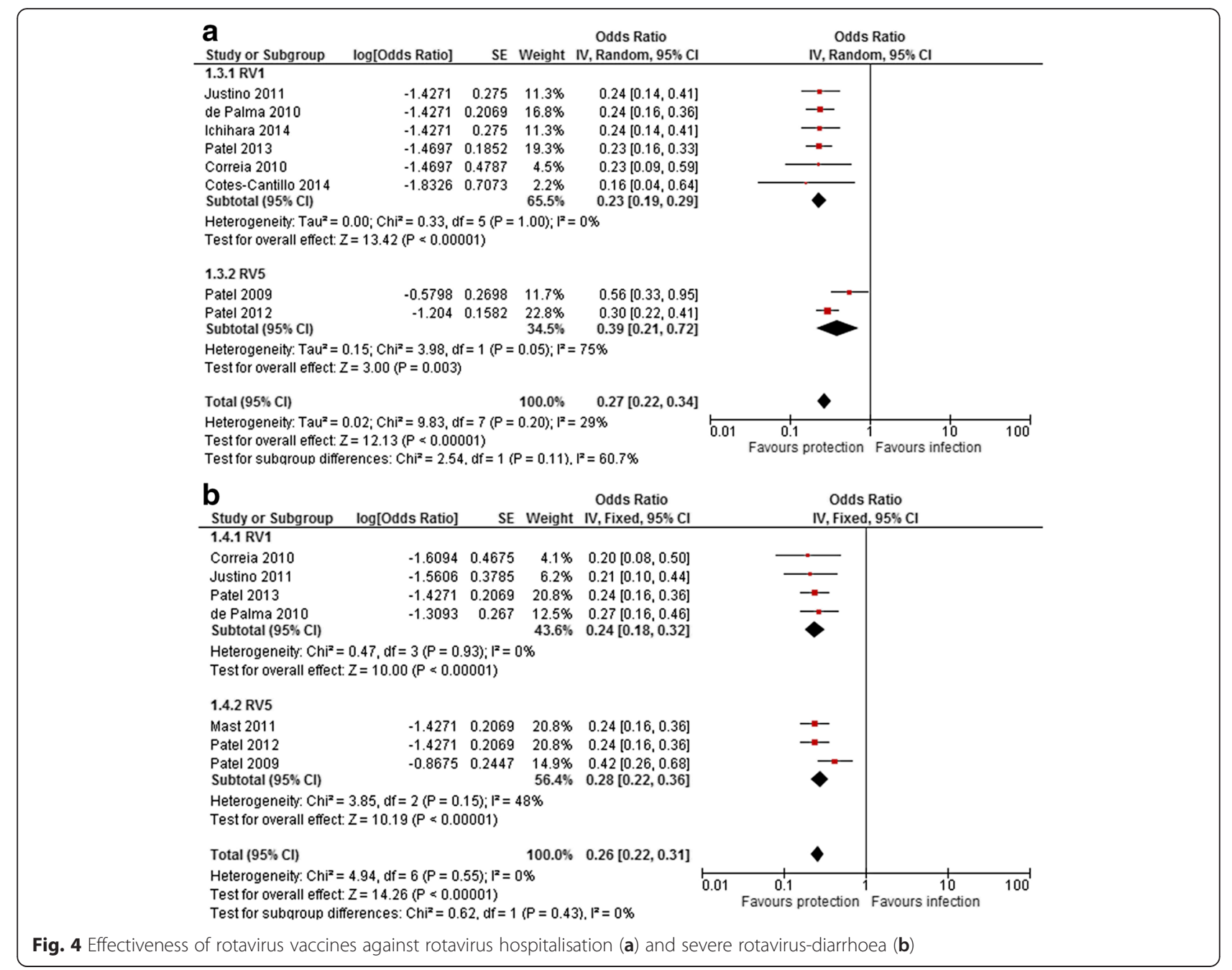

onwards and that other genotypes, such as G8P[4], G8P[6] and G3P[8] had become more frequent, suggesting that whatever the mechanism underlying these changes, genotype variation is likely to continue after vaccine introduction [70]. Further studies are needed to ascertain if the genotypes in the future represent al strains, of if genotypes for which the vaccines have lower efficacy are over-represented.

Our results should be treated with caution as the reports included have study design limitations as they used descriptive and/or ecological designs, which are not suitable to demonstrate causality. The proportion of cases due to rotavirus and genotype distributions were based on studies with different designs and laboratory methods to identify and characterise rotavirus strains. There was a high heterogeneity among the studies used to calculate the meta-proportion of rotavirus incidence. To counter this heterogeneity, we used the random effects model to minimise its impact on summary estimations. In some locations, the rotavirus proportion and genotype distribution was based on a single study reporting six countries. Countries which have not adopted the vaccine on a large scale, such as Chile and Argentine, allow private practitioners to provide rotavirus vaccinations, which provides services for a selected population of high and middle-income children. Finally, some studies reported data for one year, restricting our ability to describe strain changes over time.

\section{Conclusions}

Post-licensure studies have reported that rotavirus vaccines are effective in preventing rotavirus infection in substantial numbers of children in LA. This evidence strengthens the importance of the vaccines as an effective intervention for reducing the burden of diarrhoea and on rotavirus-specific diarrhoea. Continued surveillance after vaccine introduction is needed to monitor the long-term changes in rotavirus incidence and the potential emergence of heterotypic strains. 
Table 3 Impact of rotavirus vaccination on hospitalisation and mortality due to diarrhoea in Latin America

\begin{tabular}{|c|c|c|c|c|c|c|c|c|}
\hline \multirow{2}{*}{$\begin{array}{l}\text { Study } \\
\text { Diarrhoea mortality }\end{array}$} & \multirow[t]{2}{*}{ Country } & \multirow[t]{2}{*}{ Vaccine } & \multirow[t]{2}{*}{ Outcome } & \multicolumn{2}{|c|}{ Pre-vaccination } & \multicolumn{2}{|c|}{ Post-vaccination } & \multirow[t]{2}{*}{ Difference $(\%)$} \\
\hline & & & & Year & Results & Year & Results & \\
\hline \multirow[t]{4}{*}{ do Carmo 2011 [7] } & Brazil & RV1 & Annual death rates/100 000 children & $2002-2005$ & $<1$ yr: 48 & $2007-2009$ & $<1$ yr: 35 & -22 \\
\hline & & & & & 1 yr: 11 & & $1 \mathrm{yr}: 7$ & -28 \\
\hline & & & & & $2-4$ yr: 1 & & $2-4$ yr: 1 & -4 \\
\hline & & & & & All: 12 & & All: 9 & -22 \\
\hline \multirow[t]{3}{*}{ Gurgel 2011 [45] } & Brazil & RV1 & Number of hospitalisation & 2002-2005 & $<1$ yr: 986 & 2006-2009 & $<1$ yr: 449 & -54.5 \\
\hline & & & & & $1-4$ yr: 237 & & $1-4$ yr: 159 & -32.9 \\
\hline & & & & & All: 1223 & & All: 608 & -50.3 \\
\hline \multirow[t]{2}{*}{ Lanzieri 2011 [46] } & Brazil & RV1 & Annual death rates/100 000 children & 2004-2005 & $<1$ yr: 56.9 & 2008 & $<1$ yr: 34.9 & -39 \\
\hline & & & & & $1-4$ yr: 4.5 & & $1-4$ yr: 3.0 & -33 \\
\hline \multirow[t]{4}{*}{ Richardson 2010 [49] } & Mexico & RV1 & Annual death rates/100 000 children & 2003-2006 & $<1$ yr: 61.5 & 2008 & $<1$ yr: 25.5 & -41 \\
\hline & & & & & $1-2$ yr: 21.1 & & $1-2$ yr: 6.1 & -29 \\
\hline & & & & & $2-5$ yr: 2.9 & & $2-5$ yr: 0.2 & -7 \\
\hline & & & & & All: 18.1 & & All: 6.3 & -35 \\
\hline \multirow[t]{4}{*}{ Gastañaduy 2013 [50] } & Mexico & RV1 & Annual death rates/100 000 children & 2003-2006 & $<1$ yr: 59.1 & 2009-2011 & $<1$ yr: 28.4 & -52 \\
\hline & & & & & $1-2$ yr: 19.6 & & $1-2$ yr: 7.9 & -60 \\
\hline & & & & & $2-5$ yr: 2.8 & & $2-5 y r: 2$ & -26 \\
\hline & & & & & All: 17 & & All: 8.5 & -50 \\
\hline \multirow[t]{3}{*}{ Bayard 2012 [53] } & Panama & RV1 & Annual death rates/100 000 children & 2000-2005 & $<1$ yr: 73 & 2008 & $<1$ yr: 40 & -45 \\
\hline & & & & & $1-4$ yr: 20.3 & & $1-4$ yr: 9 & -54 \\
\hline & & & & & All: 31.1 & & All: 15.5 & -50 \\
\hline \multicolumn{9}{|l|}{ Diarrhoea hospitalisation } \\
\hline \multirow[t]{4}{*}{ do Carmo 2011 [7] } & Brazil & RV1 & Hospitalisation rates/100 000 children & $2002-2005$ & $<1$ yr: 2477 & $2007-2009$ & $<1$ yr: 1840 & -25 \\
\hline & & & & & 1 yr: 2487 & & 1 yr: 1886 & -21 \\
\hline & & & & & $2-4$ yr: 774 & & $2-4$ yr: 722 & -7 \\
\hline & & & & & All: 1429 & & All: 1165 & -17 \\
\hline \multirow[t]{3}{*}{ Gurgel 2011 [45] } & Brazil & RV1 & Number of hospitalisation & $2002-2005$ & <1 yr: 194348 & 2006-2009 & <1 yr: 125151 & -35.6 \\
\hline & & & & & $1-4$ yr: 301479 & & $1-4$ yr: 264376 & -12.3 \\
\hline & & & & & All: 495827 & & All: 389527 & -21.4 \\
\hline \multirow[t]{4}{*}{ Masukawa 2014 [47] } & Brazil & RV1 & Hospitalisation rates/100 000 children & 2000-2005 & $<1$ yr: 255.8 & 2007-2011 & $<1$ yr: 163.9 & -35.9 \\
\hline & & & & & 1 yr: 241.5 & & $1 \mathrm{yr}: 181.3$ & -24.9 \\
\hline & & & & & 2 yr: 133.2 & & $2 y r: 118.3$ & -11.2 \\
\hline & & & & & 3 yr: 83.4 & & 3 yr: 76.5 & -8.3 \\
\hline
\end{tabular}


Table 3 Impact of rotavirus vaccination on hospitalisation and mortality due to diarrhoea in Latin America (Continued)

\begin{tabular}{|c|c|c|c|c|c|c|c|c|}
\hline \multirow[t]{4}{*}{ Fernandes 2014 [48] } & Brazil, São Paulo State & RV1 & Hospitalisation rates/100 000 children & $2000-2005$ & $<1$ yr: 1009.3 & $2008-2011$ & $<1$ yr: 504.5 & -50 \\
\hline & & & & & 1 yr: 743.1 & & 1 yr: 442.5 & -40 \\
\hline & & & & & $2-4$ yr: 385.4 & & $2-4$ yr: 279.7 & -27 \\
\hline & & & & & All: 630.8 & & All: 376.6 & -40 \\
\hline \multirow[t]{6}{*}{ Yen 2011 [55] } & El Salvador & RV1 & Hospitalisation rates/100 000 children & $2005-2006$ & $<1$ yr: 499 & 2008 & $<1$ yr: 79 & -84 \\
\hline & & & & & $1-2 \mathrm{yr}: 447$ & & $1-2$ yr: 63 & -86 \\
\hline & & & & & $2-3$ yr: 123 & & $2-3$ yr: 43 & -65 \\
\hline & & & & & $3-4$ yr: 30 & & $3-4$ yr: 18 & -41 \\
\hline & & & & & $4-5$ yr: 26 & & $4-5$ yr: 8 & -68 \\
\hline & & & & & All: 225 & & All: 42 & -81 \\
\hline \multirow[t]{5}{*}{ Yen 2011 [55] } & El Salvador & RV1 & Hospitalisation rates/100 000 children & $2005-2006$ & $<1$ yr: 499 & 2009 & $<1$ yr: 106 & -79 \\
\hline & & & & & $1-2$ yr: 447 & & $1-2$ yr: 96 & -79 \\
\hline & & & & & $2-3$ yr: 123 & & $2-3$ yr: 67 & -46 \\
\hline & & & & & $4-5$ yr: 26 & & $4-5$ yr: 23 & -11 \\
\hline & & & & & All: 225 & & All: 70 & -69 \\
\hline \multirow[t]{3}{*}{ Quintanar-Solares 2011 [52] } & Mexico & RV1 & Number of hospitalisation & $2003-2006$ & $<1$ yr: 5133 & 2009 & $<1$ yr: 6597 & -40 \\
\hline & & & & & $1-2$ yr: 3944 & & $1-2$ yr: 2441 & -52 \\
\hline & & & & & $2-5$ yr: 1853 & & $2-5$ yr: 2265 & -43 \\
\hline \multirow[t]{4}{*}{ Esparza-Aguilar 2014 [51] } & Mexico & RV1 & Hospitalisation rates/10 000 children & $2003-2006$ & $<1$ yr: 684 & 2008-2011 & $<1$ yr: 358 & -48 \\
\hline & & & & & $1-2$ yr: 2301 & & $1-2$ yr: 1195 & -48 \\
\hline & & & & & $2-5$ yr: 888 & & $2-5$ yr: 733 & -18 \\
\hline & & & & & All: 945 & & All: 590 & -38 \\
\hline \multirow[t]{3}{*}{ Molto 2011 [54] } & Panama & RV1 & Number of hospitalisation & $2000-2005$ & $<1$ yr: 1359 & 2008 & $<1$ yr: 941 & -31 \\
\hline & & & & & $1-4$ yr: 2698 & & $1-4$ yr: 1614 & -40 \\
\hline & & & & & All: 4057 & & All: 2555 & -37 \\
\hline \multirow[t]{3}{*}{ Bayard 2012 [53] } & Panama & RV1 & Number of hospitalisation & $2000-2005$ & $<1$ yr: 1062 & 2008 & $<1$ yr: 762 & -28 \\
\hline & & & & & 1-4 yr: 1942 & & $1-4$ yr: 1347 & -31 \\
\hline & & & & & All: 3004 & & All: 2109 & -30 \\
\hline
\end{tabular}




\section{Additional files}

Additional file 1: Multilingual abstracts in the five official working languages of the United Nations. (PDF $412 \mathrm{~kb}$ )

Additional file 2: Supplementary appendix. (DOCX $240 \mathrm{~kb}$ )

\section{Abbreviations}

$\mathrm{Cl}$, confidence interval; EIA, enzyme immune-assay; ELISA, enzyme linked immune-assays; LA, Latin America; NOS, Newcastle-Ottawa Scale; OR, odds ratio; RT-PCR, reverse-transcription polymerase chain reaction; $R V 1$, rotarix vaccine; RV5, RotaTeq vaccine; VE, vaccine effectiveness; WHO, World Health Organization

\section{Funding}

Financial support for this study was received from calls Edital MCTI/CNPq N ${ }^{\circ}$ 14/2013 (\#471747/2013-0) and Edital MEC/MCTI/CAPES/CNPQ/FAPS - PVE 2014 (\#400723/2014-0).

\section{Authors' contributions}

VSS, LEC and RQG participated in the design of the study. VSS and PRSMF performed the statistical analysis. VSS and DPM performed the data collection. All authors wrote and approved the final manuscript.

\section{Competing interests}

The authors declare that they have no competing interests.

\section{Author details}

${ }^{1}$ Postgraduate Program in Health Sciences, Federal University of Sergipe, Rua Cláudio Batista s/n, Aracaju, Sergipe Zip code: 49060-108, Brazil. ²Department of Medicine, Federal University of Sergipe, Aracaju, Sergipe, Brazil. ${ }^{3}$ Investigative Pathology Laboratory, Federal University of Sergipe, Aracaju, Sergipe, Brazil. ${ }^{4}$ Liverpool School of Tropical Medicine, Liverpool, UK.

Received: 16 December 2015 Accepted: 18 July 2016

Published online: 12 August 2016

\section{References}

1. Lanata CF, Fischer-Walker CL, Olascoaga AC, Torres CX, Aryee MJ, Black RE. Global causes of diarrheal disease mortality in children $<5$ years of age: a systematic review. PLoS One. 2013;8:e72788.

2. Bryce J, Boschi-Pinto C, Shibuya K, Black RE. WHO estimates of the causes of death in children. Lancet. 2005;365:1147-52.

3. Linhares AC, Stupka JA, Ciapponi A, Bardach AE, Glujovsky D, Aruj PK, et al. Burden and typing of rotavirus group A in Latin America and the Caribbean: Systematic review and meta-analysis. Rev Med Virol. 2011;21(2):89-109.

4. Vesikari T, Matson DO, Dennehy P, Van Damme P, Santosham M, Rodriguez Z, et al. Safety and efficacy of a pentavalent human-bovine (WC3) reassortant rotavirus vaccine. N Engl J Med. 2006;354:23-33.

5. Ruiz-Palacios GM, Pérez-Schael I, Velázquez FR, Abate H, Breuer T, Clemens SC, et al. Safety and efficacy of an attenuated vaccine against severe rotavirus gastroenteritis. N Engl J Med. 2006;354:11-22

6. WHO. Record WE, States M, Group SA, Africa S: Rotavirus vaccines WHO position paper: January 2013 - Recommendations. Vaccine. 2013:31:6170-1.

7. do Carmo GMI, Yen C, Cortes J, Siqueira AA, de Oliveira WK, CortezEscalante JJ, et al. Decline in diarrhea mortality and admissions after routine childhood rotavirus immunization in Brazil: a time-series analysis. PLoS Med. 2011:8:e1001024.

8. Gurgel RG, Bohland AK, Vieira SCF, Oliveira DMP, Fontes PB, Barros VF, et al. Incidence of rotavirus and all-cause diarrhea in northeast Brazil following the introduction of a national vaccination program. Gastroenterology. 2009;137:1970-5.

9. Rha B, Tate JE, Payne DC, Cortese MM, Lopman BA, Curns AT, et al. Effectiveness and impact of rotavirus vaccines in the United States - 20062012. Expert Rev Vaccines. 2014;13:365-76.

10. Gurgel RQ, Cuevas LE, Vieira SCF, Barros VCF, Fontes PB, Salustino EF, et al. Predominance of rotavirus P[4]G2 in a vaccinated population, Brazil. Emerg Infect Dis. 2007;13:1571-3.

11. Gurgel RQ, Correia JB, Cuevas LE. Effect of rotavirus vaccination on circulating virus strains. Lancet. 2008;371:301-2.
12. Matthijnssens J, Nakagomi O, Kirkwood CD, Ciarlet M, Desselberger U, Van Ranst M. Group A rotavirus universal mass vaccination: how and to what extent will selective pressure influence prevalence of rotavirus genotypes? Expert Rev Vaccines. 2012:11:1347-54.

13. Zeller M, Rahman M, Heylen E, De Coster S, de Vos S, Arijs I, et al. Rotavirus incidence and genotype distribution before and after national rotavirus vaccine introduction in Belgium. Vaccine. 2010;28:7507-13.

14. Paulke-Korinek M, Kundi M, Rendi-Wagner P, de Martin A, Eder G, SchmidleLoss $B$, et al. Herd immunity after two years of the universal mass vaccination program against rotavirus gastroenteritis in Austria. Vaccine. 2011;29:2791-6.

15. Wang H, Menzies R, Macartney K. Changes in hospitalisations for acute gastroenteritis in Australia after the national rotavirus vaccination program. Med J Aust. 2012:197:453-7.

16. Leshem E, Lopman B, Glass R, Gentsch J, Bányai K, Parashar U, et al. Distribution of rotavirus strains and strain-specific effectiveness of the rotavirus vaccine after its introduction: a systematic review and metaanalysis. Lancet Infect Dis. 2014;3099:1-10.

17. Oliveira LH, Camacho LAB, Coutinho ESF, Ruiz-Matus C, Leite JPG. Rotavirus vaccine effectiveness in Latin American and Caribbean countries: A systematic review and meta-analysis. Vaccine. 2015;33 Suppl 1:A248-54.

18. Country and Lending Groups | Data [http://data.worldbank.org/about/ country-and-lending-groups]. Accessed Nov 2015

19. Wells $G$, Shea B, O'Connell D, Peterson J, Welch V, Losos M, et al. The Newcastle-Ottawa Scale (NOS) for assessing the quality of nonrandomised studies in meta-analyses. Available: http://www.ohri.ca/programs/clinical_ epidemiology/oxford.asp. Accessed May 2015.

20. Freeman MF, Tukey JW. Transformations Related to the Angular and the Square Root. Ann Math Stat. 1950:21:607-11.

21. Miller JJ. The Inverse of the Freeman - Tukey Double Arcsine Transformation. Am Stat. 1978;32:138-8.

22. Newcombe RG. Two-sided confidence intervals for the single proportion: comparison of seven methods. Stat Med. 1998;17:857-72.

23. Higgins JPT, Thompson SG. Quantifying heterogeneity in a meta-analysis. Stat Med. 2002;21:1539-58.

24. Roig CG, Larre N, Pastene H, García Roig C, Larre N, Pastene H, et al Epidemiological and clinical characteristics of acute gastroenteritis according to their etiology (rotavirus or other) in children younger than 5 years old at a private institution in the city of Buenos Aires. Arch Argent Pediatr. 2013;111:218-23.

25. Carvalho-Costa FA, Araújo IT, Santos de Assis RM, Fialho AM, de Assis Martins CMM, Bóia MN, et al. Rotavirus genotype distribution after vaccine introduction, Rio de Janeiro, Brazil. Emerg Infect Dis. 2009;15:95-7.

26. Correia JB, Patel MM, Nakagomi O, Montenegro FMU, Germano EM, Correia $\mathrm{NB}$, et al. Effectiveness of monovalent rotavirus vaccine (Rotarix) against severe diarrhea caused by serotypically unrelated G2P[4] strains in Brazil. J Infect Dis. 2010;201:363-9.

27. Silva ML, Souza JR, Melo MMM. Rotavirus prevalence in infants and children in the public healthcare system of the state of Pernambuco. Rev Soc Bras Med Trop. 2010;43:548-51.

28. Borges AMT, Dias e Souza M, Fiaccadori FS, Cardoso das D de P D. Monitoring the circulation of rotavirus among children after the introduction of the Rotarix ${ }^{\text {TM }}$ vaccine in Goiânia, Brazil. Mem Inst Oswaldo Cruz. 2011;106:499-501.

29. Justino MCA, Linhares AC, Lanzieri TM, Miranda Y, Mascarenhas JDP, Abreu $E$, et al. Effectiveness of the monovalent G1P[8] human rotavirus vaccine against hospitalization for severe G2P[4] rotavirus gastroenteritis in Belém, Brazil. Pediatr Infect Dis J. 2011;30:396-401.

30. Vieira SCF, Gurgel RQ, Kirby A, Barreto IP, Souza LD, Oliveira OC, et al. Acute diarrhoea in a community cohort of children who received an oral rotavirus vaccine in Northeast Brazil. Mem Inst Oswaldo Cruz. 2011;106:330-4.

31. Sandra CA, Estevam GK, Penati M, Soares LA, Ferreira RG, Orlandi PP, et al. Detection of rotavirus in children with acute gastroenteritis in Porto Velho, Rondonia, Brazil. Arch Virol. 2014;159:1139-42.

32. Yen C, Figueroa JR, Uribe ES, Del Carmen-Hernández L, Tate JE, Parashar UD, et al. Monovalent rotavirus vaccine provides protection against an emerging fully heterotypic G9P[4] rotavirus strain in Mexico. J Infect Dis. 2011;204:783-6.

33. Maldonado A, Franco MC, Blanco A, de Villalobos BL, Martínez R, Hagel I, et al. Clinical and epidemiological characteristics of rotavirus infection in children of Cumaná. Venezuela Invest Clin. 2010:51(4):519-29.

34. Patel MM, Patzi M, Pastor D, Nina A, Roca $Y$, Alvarez $L$, et al. Effectiveness of monovalent rotavirus vaccine in Bolivia: case-control study. BMJ. 2013;346:f3726. 
35. de Palma O, Cruz L, Ramos H, de Baires A, Villatoro N, Pastor D, et al. Effectiveness of rotavirus vaccination against childhood diarrhoea in $\mathrm{El}$ Salvador: case-control study. BMJ. 2010;340:c2825.

36. Patel M, Pedreira C, De Oliveira LH, Tate J, Orozco M, Mercado J, et al. Association between pentavalent rotavirus vaccine and severe rotavirus diarrhea among children in Nicaragua. JAMA. 2009;301:2243-51.

37. Becker-Dreps S, Paniagua M, Zambrana LE, Bucardo F, Hudgens MG, Weber DJ, et al. Rotavirus prevalence in the primary care setting in Nicaragua after universal infant rotavirus immunization. Am J Trop Med Hyg. 2011;85:957-60.

38. Mast TC, Khawaja S, Espinoza F, Paniagua M, Palacio Del Carmen L, Cardellino A, et al. Case-control study of the effectiveness of vaccination with pentavalent rotavirus vaccine in Nicaragua. Pediatr Infect Dis J. 2011;30:e209-15.

39. Bucardo F, Rippinger CM, Svensson L, Patton JT. Vaccine-derived NSP2 segment in rotaviruses from vaccinated children with gastroenteritis in Nicaragua. Infect Genet Evol. 2012;12:1282-94.

40. Patel M, Pedreira C, de Oliveira LH, Umana J, Tate J, Lopman B, et al. Duration of Protection of Pentavalent Rotavirus Vaccination in Nicaragua. Pediatrics. 2012;130:e365-72.

41. Bucardo F, Reyes $Y$, Svensson L, Nordgren J. Predominance of norovirus and sapovirus in Nicaragua after implementation of universal rotavirus vaccination. PLoS One. 2014;9:e98201.

42. Ichihara MYT, Rodrigues LC, Teles Santos CAS, Teixeira MDGLC, de Jesus SR, Alvim De Matos SM, et al. Effectiveness of rotavirus vaccine against hospitalized rotavirus diarrhea: A case-control study. Vaccine. 2014;32:2740-7.

43. Cotes-Cantillo K, Paternina-Caicedo A, Coronell-Rodríguez W, Alvis-Guzmán $\mathrm{N}$, Parashar UD, Patel M, et al. Effectiveness of the monovalent rotavirus vaccine in Colombia: a case-control study. Vaccine. 2014;32:3035-40.

44. Patel MM, Parashar UD. Assessing the effectiveness and public health impact of rotavirus vaccines after introduction in immunization programs. J Infect Dis. 2009;200 Suppl Suppl 1:S291-9.

45. Gurgel RQ, llozue C, Correia JB, Centenari C, Oliveira SMT, Cuevas LE. Impact of rotavirus vaccination on diarrhoea mortality and hospital admissions in Brazil. Trop Med Int Health. 2011;16:1180-4.

46. Lanzieri TM, Linhares AC, Costa I, Kolhe DA, Cunha MH, Ortega-Barria E, et al. Impact of rotavirus vaccination on childhood deaths from diarrhea in Brazil. Int J Infect Dis. 2011;15:e206-10.

47. Masukawa M de LT, Moriwaki AM, Uchimura NS, de Souza EM, Uchimura TT. Intervention analysis of introduction of rotavirus vaccine on hospital admissions rates due to acute diarrhea. Cad Saude Publica. 2014:30:2101-11.

48. Fernandes EG, Sato HK, Leshem E, Flannery B, Konstantyner TCRDO, Veras MADSM, et al. Impact of rotavirus vaccination on diarrhea-related hospitalizations in São Paulo State, Brazil. Vaccine. 2014;32:3402-8.

49. Richardson V, Hernandez-Pichardo J, Quintanar-Solares M, Esparza-Aguilar M, Johnson B, Gomez-Altamirano CM, et al. Effect of rotavirus vaccination on death from childhood diarrhea in Mexico. N Engl J Med. 2010;362:299-305.

50. Gastañaduy PA, Sánchez-Uribe E, Esparza-Aguilar M, Desai R, Parashar UD, Patel $M$, et al. Effect of rotavirus vaccine on diarrhea mortality in different socioeconomic regions of Mexico. Pediatrics. 2013;131:e1115-20.

51. Esparza-Aguilar M, Gastañaduy PA, Sánchez-Uribe E, Desai R, Parashar UD, Richardson $V$, et al. Diarrhoea-related hospitalizations in children before and after implementation of monovalent rotavirus vaccination in Mexico. Bull World Health Organ. 2014;92:117-25.

52. Quintanar-Solares M, Yen C, Richardson V, Esparza-Aguilar M, Parashar UD, Patel MM. Impact of rotavirus vaccination on diarrhea-related hospitalizations among children $<5$ years of age in Mexico. Pediatr Infect Dis J. 2011;30(1 Suppl):S11-5.

53. Bayard V, DeAntonio R, Contreras R, Tinajero O, Castrejon MM, Ortega-Barría

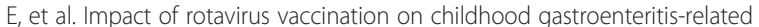
mortality and hospital discharges in Panama. Int J Infect Dis. 2012;16:94-8.

54. Molto Y, Cortes JE, de Oliveira LH, Mike A, Solis I, Suman O, et al. Reduction of diarrhea-associated hospitalizations among children aged $<5$ Years in Panama following the introduction of rotavirus vaccine. Pediatr Infect Dis J. 2011:30(1 Suppl):S16-20

55. Yen C, Armero Guardado JA, Alberto P, Rodriguez Araujo DS, Mena C, Cuellar $E$, et al. Decline in rotavirus hospitalizations and health care visits for childhood diarrhea following rotavirus vaccination in El Salvador. Pediatr Infect Dis J. 2011;30(1 Suppl):S6-10
56. Linhares AC, Velázquez FR, Pérez-Schael I, Sáez-Llorens X, Abate H, Espinoza $F$, et al. Efficacy and safety of an oral live attenuated human rotavirus vaccine against rotavirus gastroenteritis during the first 2 years of life in Latin American infants: a randomised, double-blind, placebo-controlled phase III study. Lancet. 2008;371:1181-9.

57. Karafillakis E, Hassounah S, Atchison C. Effectiveness and impact of rotavirus vaccines in Europe, 2006-2014. Vaccine. 2015;33:2097-107.

58. Cunliffe NA, Witte D, Ngwira BM, Todd S, Bostock NJ, Turner M, et al. Efficacy of human rotavirus vaccine against severe gastroenteritis in Malawian children in the first two years of life: a randomised, double-blind, placebo controlled trial. Vaccine. 2012;30:1-16.

59. Madhi SA, Kirsten M, Louw C, Bos P, Aspinall S, Bouckenooghe A, et al. Efficacy and immunogenicity of two or three dose rotavirus-vaccine regimen in South African children over two consecutive rotavirus-seasons: A randomized, double-blind, placebo-controlled trial. Vaccine. 2012:30 Suppl 1:44-51.

60. Takemoto MLS, Bahia L, Toscano CM, Araujo DV. Systematic review of studies on rotavirus disease cost-of-illness and productivity loss in Latin America and the Caribbean. Vaccine. 2013;31 Suppl 3:C45-57.

61. Atherly D, Dreibelbis R, Parashar UD, Levin C, Wecker J, Rheingans RD. Rotavirus vaccination: cost-effectiveness and impact on child mortality in developing countries. J Infect Dis. 2009;200 Suppl 1:S28-38.

62. de Oliveira LH, Danovaro-Holliday MC, Andrus JK, de Fillipis AMB, Gentsch J, Matus CR, et al. Sentinel hospital surveillance for rotavirus in latin american and Caribbean countries. J Infect Dis. 2009;200 Suppl 1:S131-9.

63. Kane EM, Turcios RM, Arvay ML, Garcia S, Bresee JS, Glass RI. The epidemiology of rotavirus diarrhea in Latin America. Anticipating rotavirus vaccines. Rev Panam Salud Publica. 2004;16:371-7.

64. Santos N, Hoshino Y. Global distribution of rotavirus serotypes/genotypes and its implication for the development and implementation of an effective rotavirus vaccine. Rev Med Virol. 2005;15:29-56.

65. Gurgel RQ, Cunliffe NA, Nakagomi O, Cuevas LE. Rotavirus genotypes circulating in Brazil before national rotavirus vaccination: a review. J Clin Virol. 2008:43:1-8.

66. Matthijnssens J, Zeller M, Heylen E, De Coster S, Vercauteren J, Braeckman T, et al. Higher proportion of G2P[4] rotaviruses in vaccinated hospitalized cases compared with unvaccinated hospitalized cases, despite high vaccine effectiveness against heterotypic G2P[4] rotaviruses. Clin Microbiol Infect. 2014;20:0702-10.

67. Bourdett-Stanziola L, Jiménez C, Ortega-Barria E. Diversity of human rotavirus $\mathrm{G}$ and $\mathrm{P}$ genotypes in Panama, Costa Rica, and the Dominican Republic. Am J Trop Med Hyg. 2008;79:921-4.

68. Ribas M de los A, Nagashima S, Calzado A, Acosta G, Tejero Y, Cordero Y, et al. Emergence of G9 as a predominant genotype of human rotaviruses in Cuba. J Med Virol. 2011;83:738-44.

69. Nakagomi T, Cuevas LE, Gurgel RG, Elrokhsi SH, Belkhir YA, Abugalia M, Dove W, Montenegro FMU, Correia JB, Nakagomi O, Cunliffe NA, Hart CA. Apparent extinction of non-G2 rotavirus strains from circulation in Recife, Brazil, after the introduction of rotavirus vaccine. Arch Virol. 2008;153:591-3.

70. Gurgel RQ, Alvarez ADJ, Rodrigues A, Ribeiro RR, Dolabella SS, da Mota NL, et al. Incidence of Rotavirus and Circulating Genotypes in Northeast Brazil during 7 Years of National Rotavirus Vaccination. PLoS One. 2014;9:e110217.

\section{Submit your next manuscript to BioMed Central and we will help you at every step:}

- We accept pre-submission inquiries

- Our selector tool helps you to find the most relevant journal

- We provide round the clock customer support

- Convenient online submission

- Thorough peer review

- Inclusion in PubMed and all major indexing services

- Maximum visibility for your research

Submit your manuscript at www.biomedcentral.com/submit 